\title{
Willamette water 2100: river basins as complex social-ecological systems
}

\author{
M. Santelmann ${ }^{1}$, J. McDonnell ${ }^{1}$, J. Bolte ${ }^{1}$, S. Chan ${ }^{1}$, \\ A. T. Morzillo ${ }^{1} \&$ D. Hulse ${ }^{2}$ \\ ${ }^{1}$ Oregon State University, Oregon, USA \\ ${ }^{2}$ University of Oregon, Oregon, USA
}

\begin{abstract}
This paper describes a project to model river basins as complex social-ecological systems. We propose hypotheses about system resilience to water scarcity and climate change that can be examined with an agent-based modeling approach, and outline a methodology integrating hydrology, ecology, economics, engineering and stakeholder inputs to test these hypotheses using the Willamette River Basin (Oregon, USA) as an example system. The response of society to change is often overlooked in studies that focus primarily on the biophysical sciences to develop alternative future scenarios and predict system responses. If the interactions between society and the ecological system are poorly represented or left out of modeling approaches, this will compromise our understanding of feedbacks to the system, and the potential consequences of policy or management actions. Through Stakeholder Learning Action Networks we are gathering project-relevant knowledge in a co-learning environment on water use, management, policies and issues that impact stakeholders, and the types of project outputs desired by stakeholders. This information is useful for understanding the social- ecological system feedbacks, anticipating water scarcity, and informing integrative water systems responses. Modeling tools that can generate and explore alternative outcomes based on different sets of social and ecological conditions and their interaction within the system could also lead to a better understanding of ecosystem resilience and help guide decision making in the face of climate change and potential water scarcity.

Keywords: resilience, water scarcity, adaptive cycles, complex adaptive systems, stakeholder learning and action networks.
\end{abstract}




\section{Introduction}

In the nearly four decades that have passed since the seminal paper by Holling [1] on resilience and stability in ecological systems, much intellectual effort has been expended in the development of resilience theory and associated conceptual models of complex adaptive systems and adaptive cycles [2-5]. Although there have been notable applications of resilience theory to ecological systems [6] or social systems, with a few exceptions $[7,8]$ these studies have focused on the biophysical system or the social system rather than the coupled system with feedbacks between the two. Much of what has been written about resilience in social-ecological systems (defined as linked systems of people and nature) has tended to focus on case studies describing how these systems fit the conceptual model of resilience theory, illustrate the operation of adaptive cycles, and exemplify the dynamics of a complex adaptive system (CAS) [3, 4, 9].

While the case studies used to describe the application of resilience theory to social-ecological systems as examples of a CAS are interesting and compelling, they are essentially post-mortems, describing how once-healthy coral reef or lake ecosystems illustrate the conceptual model of adaptive cycles after the system has moved to an alternative, degraded state. To date, most efforts to examine resilience theory have focused on modeling ecological systems or social systems. There have been very few efforts to model social-ecological systems. In part, this is because the theory is relatively young, and in part, because building even a simple model of a social-ecological system capable of incorporating feedbacks from the social as well as the ecological system is a non-trivial task.

We would not be in the position to take the next steps in studying resilience without the pioneering work of Holling and others to develop and refine resilience theory $[1,2,5]$ and conceptual models of adaptive cycles in socialecological systems [3-10]. As with any theory, the basic principles, concepts, and specific vocabulary of resilience theory had to be developed and defined. Here, we use the definition of resilience as "the capacity of an ecosystem to tolerate disturbance without collapsing into a qualitatively different state that is controlled by a different set of processes" [5]. This concept of resilience as applied to dynamic ecological and social-ecological systems has a very different meaning than the concept of resilience as applied to engineered systems (the ability of the system to resist disturbance and the rate at which it returns to equilibrium following disturbance, assuming the system is near equilibrium).

The next step towards improving our understanding of social-ecological systems requires models that can incorporate feedbacks from social as well as biophysical systems into the operations of the complex system, and places that can serve as test beds for such a model. The agent-based model, Envision, has been developed to investigate the effects of alternative policies on landscapes in the Pacific Northwest region, and is being applied by our research group to explore the potential consequences of alternative policies and decisions in the Willamette River Basin (WRB) with respect to water scarcity.

Here, we present our approach for using Envision to investigate the dynamics of the water system in the WRB as an example of both a CAS and a social- 
ecological system. We outline the ways in which this approach can provide insights concerning resilience in social-ecological systems, and help test hypotheses about the nature of stocks and flows of capital and connectedness in adaptive cycles. We begin by describing river basins as both complex adaptive systems and social-ecological systems. Next, we discuss how the WRB provides the opportunity for studying the dynamics of these systems owing to the wealth of information available as a result of prior research and activities conducted on the current project. We then describe the agent-based model, Envision, and its application to explore the resilience of the WRB with respect to water scarcity, and discuss ideas for transferring the approach to other systems. Finally, we outline our approach to analyze modeled outcomes with respect to place as well as to policy scenario characteristics and stakeholder decisions, particularly as they reflect efforts to manage for resilience at different scales and in other regions. Results of modeled outcomes will be used to explore system dynamics and test hypotheses about system response to policies promoting the maintenance of the status quo in a changing system as compared to those policies that attempt to foster resilience. Resilience of the system with respect to water scarcity will be measured at different scales in the basin, and expressed as the probability that the system will not cross a water scarcity threshold, moving from a state of non-scarcity to a state of scarcity. We define vulnerability as the opposite probability that the system will cross a water scarcity threshold moving to a state of scarcity from a state of non-scarcity. In the context of this project, we will define scarcity as the marginal value of a unit of water in a specific time and place in the basin.

\section{River basins as complex adaptive systems}

River basins are examples of complex adaptive systems, comprising nested sets of social-ecological systems which function at successively smaller scales in time and space (e.g., river basin, sub-basin, watershed, irrigation district, catchment, municipality), yet interact and are linked $[2,4]$. The structure and functioning of a CAS can be envisioned as a dynamic hierarchy of nested sets of adaptive cycles that influence the structure and function of the larger system over time and are themselves influenced by that larger system, fig. 1.

\subsection{Defining complex adaptive systems}

Levin [2] defines the three essential components of a CAS as (a) sustained diversity and individuality of components, (b) localized interactions among components, and (c) an autonomous process that selects from among components a subset for replication or enhancement. River basins fit Levin's description of a CAS in that they can be divided into components of increasingly smaller spatial extent, from sub-basin to catchments, each with a degree of diversity and individuality based not only on biophysical but also social and economic attributes. There are localized interactions among components, and there can be autonomous processes that select from among those components a 
subset for enhancement or replication. For example, management practices that have been successful in one watershed can be applied to management of similar watersheds in attempts to replicate those successes. Thus, the components within the CAS have the capacity to self-organize, and interactions among components can influence the system at both higher and lower levels of organization.

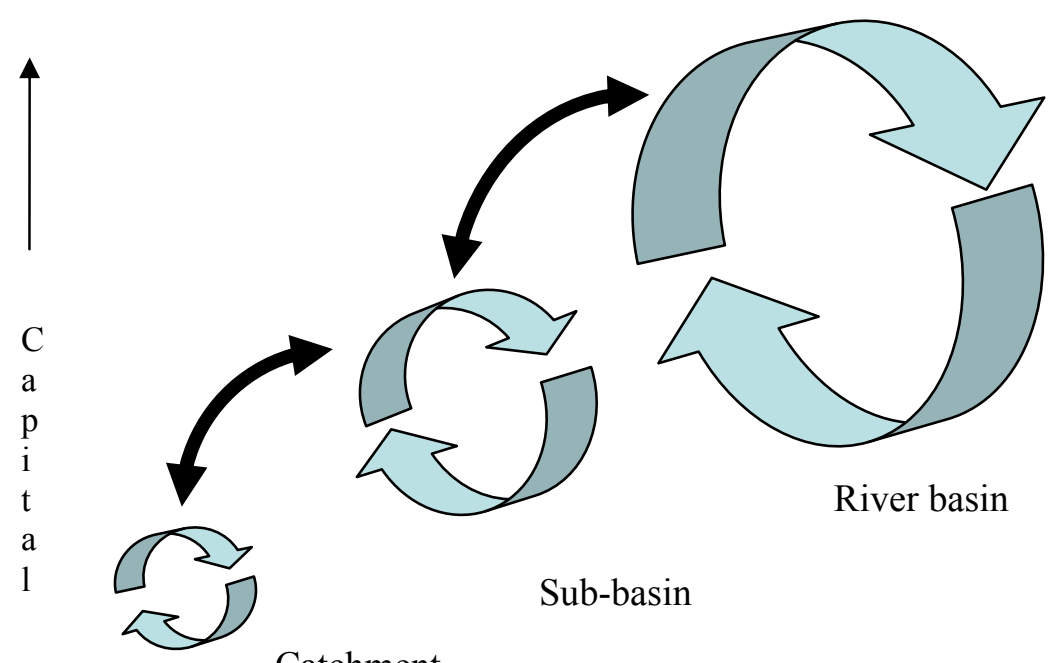

Catchment

\section{Connectedness}

Figure 1: Nested hierarchies of linked adaptive cycles within a river basin.

\subsection{The Willamette River basin}

The Willamette River is a tributary of the Columbia River and the tenth largest river in the United States based on average annual flow. The watershed area is $29-798 \mathrm{~km}^{2}$, about 12 percent of the land area of the state of Oregon. It is home to 2.7 million people (69\% of the population of Oregon) and has grown at a rate of about $12 \%$ in the past decade ending in 2010. It contains Portland, Salem, and Eugene, three of the largest cities in Oregon. About $31 \%$ of the timber harvested and $45 \%$ of the market value of agricultural commodities in the state are produced in the WRB [11]. From the confluence of the North Fork and Middle Fork of the Willamette River in Eugene, the Willamette River flows approximately 300 kilometers north to Portland, where it joins the Columbia River. The watershed comprises twelve sub-basins (United States Geological Survey (USGS) fourth-field hydrologic units), that have been subdivided into seventy-seven USGS fifth-field hydrologic units (watersheds). Headwater elevations range from over $1200 \mathrm{~m}$ in the Coast Range on the west side of the basin to over $3000 \mathrm{~m}$ in the Cascades, which form the eastern margin of the basin. The climate is characterized by cool, wet winters and warm, dry summers. 
Summer rainfall makes up only $5 \%$ of the annual average total, which ranges from $950 \mathrm{~mm}$ to over $2000 \mathrm{~mm}$. Recent research [12] indicates that under scenarios of future climate change, snowfall may convert to rainfall over $22 \%$ of the area in the Oregon Cascades, reducing mountain-front recharge of groundwater and diminishing summer flows in streams. Paradoxically, a region with seemingly abundant water may experience water scarcity as a result of changes in timing and nature of precipitation, anticipated population growth and increasing water demand. Ecological, hydrologic, social and economic research in the region has led to a wealth of long-term, spatially-specific data sets at multiple scales in the basin, and an array of disciplinary models have been successfully applied in the WRB [13-18], making it feasible to model this system using water scarcity to define system state as described below.

\section{Agent-based modelling of the WRB with Envision}

The agent-based model Envision [19-21] is a framework that integrates multiple models of landscape change, feedbacks from emerging scarcities, and multiagent representations of human decision-making across hydrological, ecological, social, and economic dimensions of change, within a spatially- and temporallyexplicit framework that allows rapid exploration of alternative future scenarios. It is well-suited for the study of resilience in social-ecological systems owing to its capability of incorporating output from social, economic, hydrologic, and ecological models as feedback that results from specific policy scenarios applied to the landscape. Envision has been developed with specific attention to model transferability to other systems. This transferability is achieved by using Envision architecture as a framework that connects other "pluggable" disciplinary models relevant to the region and questions of interest.

\subsection{How envision works}

Envision enables disciplinary models to communicate via a landscape, a shared data repository that represents current conditions at specific locations. Each time a model ends a run, it outputs its results to the landscape. Each time a plug-in model begins a run, it draws its inputs from the landscape. Envision synchronizes the operation of the plug-in models as it runs them in parallel. As Envision steps through time, each model draws from the landscape timely input data based on calculations by the other models. In this way, an economic model that represents hydrological factors in a cursory manner can take advantage of the calculations made by a hydrological model during the previous time interval. The Envision framework thereby enables disciplinary models to gain in predictive power by combining the enhanced capabilities of the disciplinary models synergistically. Envision also contains an integrated multi-agent-based modeling component that can represent the impact of human decision making on landscape change. Envision defines agents as entities with decision-making authority, such as federal land managers, agricultural producers, or homeowners, (treated in the aggregate, not as individuals). Within the Envision framework, agents make 
decisions based on the current conditions of the evolving landscape, landscape feedbacks from emerging scarcities, agent values, and constraints such as laws and policies. A set of policies and model parameterization constitutes a scenario.

\subsection{A new paradigm in modeling complex social-ecological systems}

Envision represents a new paradigm in water research in three respects. First, it integrates a broad range of disciplinary models. Second, it has the ability to consider the impact and interactions of policies and human decision making on the landscape and use landscape change as feedback into the model. Third, it replaces the traditional "predict-then-act" paradigm with a novel "explore-thentest" paradigm. In the "predict-then-act" modeling paradigm, one predicts a range of future outcomes, selects the optimal outcome, and then takes the action most likely to realize it. The difficulty with this approach is that in a complex environment such as a water system under uncertain future climate conditions, the degree of uncertainty is so high that a strategy aimed at realizing an optimal outcome may fail or prove irrelevant. In contrast, an "explore-then-test" paradigm looks at many possible outcomes and tries to identify policies or mitigation strategies that produce acceptable outcomes for a broad range of them. Rather than looking for the best strategy, it looks for resilient strategies that are unlikely to fail [21]. Envision is well-suited to the "explore-then-test" paradigm, and for the study of resilience in social-ecological systems.

\subsection{Using envision to study resilience and the nature of CAS}

While the focus of the project is to investigate system dynamics with respect to water scarcity in the WRB under conditions of changing climate and population, the project also provides the opportunity to explore theoretical questions about the resilience of the WRB as a CAS. The integrated study of the water system in the WRB will lead to an improved understanding of the linkages and feedbacks among hydrologic, economic, social, and ecological dimensions of the water system, which can be incorporated into Envision. The Envision model can then be used as a tool to explore system response to various policies and decisions that affect supply of and demand for water among different sectors, the emergence of scarcity at different spatial and temporal scales, and subsequent responses of society to scarcity. We will use Envision for questions such as; where and when will climate change and human activity create water scarcity? at what scale will scarcity tend to emerge? We can also address questions such as; what attributes of different policy scenarios lead to a more resilient system? what attributes of watersheds within the WRB tend to foster resilience? and, at what scales do innovation or diversity in societal response develop?

Envision could also be used to investigate hypotheses about adaptive cycles and the dynamics of social-ecological systems, as discussed in the next section. 


\subsection{Adaptive cycles and stocks and slows of capital}

The conceptual model of adaptive cycles as a fundamental construct for understanding the dynamics of complex systems, from cells to ecosystems and societies, was initiated by Holling [22]. He posited the existence of adaptive cycles that alternate between long periods of aggregation of capital and increased connectedness in the system and shorter periods following collapse in which accumulated capital is released, connections are broken, and opportunities for innovation are created. This conceptual model was further developed by Gunderson and others [3-23] for application to social-ecological systems. Adaptive cycles are represented as consisting of four stages: 1. exploitation (r), 2 . conservation $(\mathrm{K}), 3$. release $(\Omega)$, and 4. re-organization $(\alpha)$, and two major phases; the foreloop (movement from $r$ to $\mathrm{K}$ stages in a slow, incremental phase of growth and accumulation), and the backloop (movement from $\Omega$ to $\alpha$ stages in a rapid phase of collapse and reorganization leading to renewal).

The difficulty with this conceptual model as it has been articulated is that it is untestable. In order to test this conceptual model of adaptive cycles, one must be able to explicitly define (a) system state with respect to structures (stocks) and processes (flows) relevant to system state, (b) what is accumulating and (c) what processes are becoming increasingly connected. There must also be some way to quantify accumulation of capital and connectedness of processes in the system and identify thresholds at which the system changes state. However, the field has been moving in the opposite direction, suggesting that the adaptive cycle is a metaphor rather than a testable hypothesis [10]. Correspondingly, the conceptual model of the adaptive cycle has changed over time from a figure-eight of four stages with $\mathrm{x}$ - and $\mathrm{y}$ - axes representing capital and connectedness, to an abstract one in which foreloop and backloop float in an undefined plane [4].

A model of a river basin as a CAS with explicitly defined system state (water scarcity), structures and processes (compartments of water and hydrologic flows as well as economic and governance processes relevant to the dynamics of the water system), can provide an opportunity to explore and test the conceptual model of adaptive cycles and resilience. Key tasks are to define and measure what is being lost or accumulating (forms of capital), to identify and describe important processes that govern flows and processes relevant to the water system, and to measure connectedness of those processes. Model outputs must provide a way to measure capital accumulation and connectedness of processes, and identify thresholds at which the system changes state.

We propose here a hypothesis modifying the concept of adaptive cycles, suggesting that accumulation of capital and increased connectedness per se may not produce a system ripe for collapse (Holling's "accident waiting to happen") but rather asymmetry in the accumulation of and flows among the various types of capital in the system $[24,25]$ may make the system vulnerable. We define here five forms of capital as they relate to the resilience of the system with respect to water scarcity: Financial capital-wealth in the form of money or assets produced by stocks of water; Physical capital-infrastructure associated with water storage, distribution and management; Natural capital-stocks of water and 
elements of the ecosystem that provide flows of (water-related) ecosystem goods and services, including all ecosystem components (vegetation, soils, aquifers) involved in storage of stocks and provision of flows of water, as well as those components that influence water quality (such as riparian forests that shade streams, filter strips, field margins, or wetlands that remove excess nutrients and filter sediment); Human capital-aspects of people (health, education, abilities and talents, or other attributes involving competence, knowledge and personal attributes) that can provide services such as research capacity, skilled labor, innovation, or inspiration to the community, especially with respect to management of water resources; and Social capital-social relationships and institutions that have productive benefits with respect to water management .

For example, assume that there is an optimum proportion of the capital of each type (Natural, Financial, Physical, Human, and Social), as diagrammed in fig. $2 a$, that characterizes the system over some fundamental unit of space and time. Amounts of capital relative to the optimum are shown in fig. 2 by distance of each stock of that capital (oval shape) from the centroid (pentagon shape). The size of the shape representing stocks can illustrate diversity (richness and equitability of distribution within the system) for that stock of capital, allowing comparisons of systems which differ in diversity of functional types of a specific type of capital.

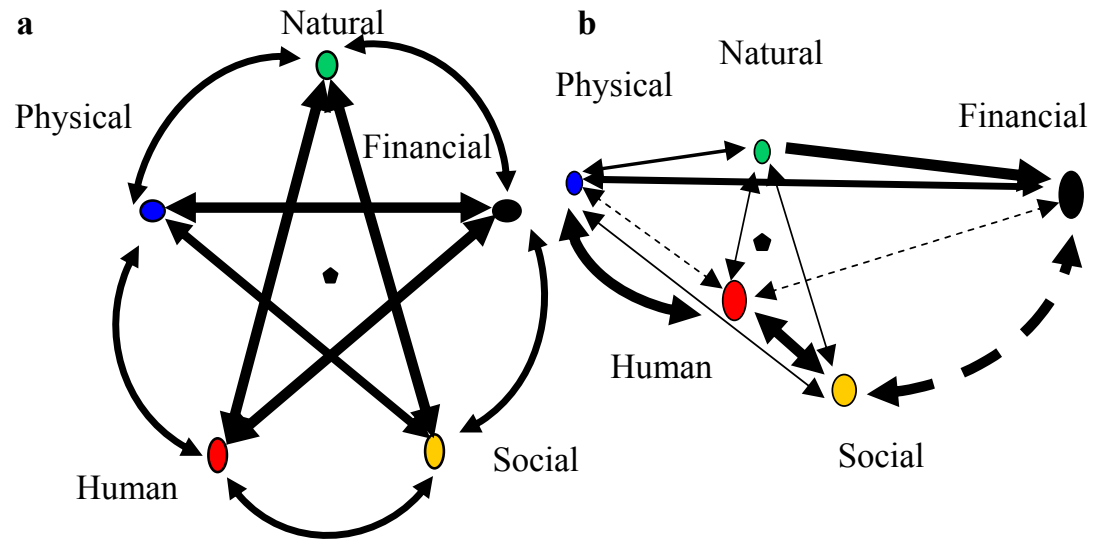

Figure 2: Symmetry and asymmetry among various types of capital in a CAS.

Next, consider a hypothetical system as in fig. $2 b$, in which stocks of natural capital are much lower relative to the optimum, as substantial amounts of natural capital have been converted to financial capital by damming streams in the system for hydropower, and withdrawing water for irrigation. This results in asymmetry in stocks of capital, and entrainment (bold arrows) of some processes of capital flow. In this heuristic example, flow of natural capital is entrained into financial capital. Human capital, in the form of knowledge and expertise is used primarily to generate physical capital (dams, irrigation systems, etc.). As 
diagrammed here, human capital has decreased owing to loosely connected flows of financial capital to develop human capital (dashed arrows). Social capital (relationships and institutions for managing water) remains relatively high owing to strength of relationships and institutions required for managing the water, such as water control districts and irrigation districts. This hypothetical system as diagrammed may be vulnerable to water scarcity, particularly with respect to quantities and quality of water available for aquatic life. The level of scarcity could be assessed as the probability of crossing some pre-defined threshold of marginal value for a unit of water for this location at a particular time.

Using this concept of multiple types of capital and flows as representing system connectedness, one could plot relative proportions of multiple types of capital for various systems along axes of capital and connectedness (as in fig. 1), generating a braid rather than a loop for the phases of the adaptive cycle. If different types of capital differ in their accumulation relative to optimal proportions as the system becomes more connected, the braid tends to unravel, producing a more vulnerable system. The Envision model could be used to explore the hypothesis that asymmetry in capital stocks and flows make a system more vulnerable, and other hypotheses about patterns of stocks and flows in the system, first in the WRB and eventually, for other river basins.

\section{Stakeholder Learning Action Networks: a tool to define, understand and model social-ecological systems}

A critically important part of our approach is our Stakeholder Learning Action Networks (SLANs), which provide a forum for collaborative learning among project researchers as well as a diverse set of decision makers and managers of land and water systems within the region [26]. Through these SLANs, we are gathering project-relevant knowledge on water use, management, policies and issues that impact stakeholders from stakeholders. We are building a community that will engage in participatory development of policy scenarios and that can help our modeling teams understand the potential responses of decision makers to changes in the water system or water governance at various scales. We rely on the managers and policy makers who participate in these SLANs to help us understand the current system, the types of project outputs desired by decisionmakers and to develop a plausible array of strategies that could be used at different scales within the basin to prevent, mitigate, or adapt to water scarcity that will be incorporated as feedback into the Envision model.

\section{Transferring the approach to other regions}

Because population growth and climate change are global phenomena, we look forward to testing the transferability of the WRB approach and conceptual foundation to other systems. A typology of hydrological landscape regions (HLRs), classifications of geographic regions which take into account their climate, topography, soil properties, and aquifer permeability, has been developed for the WRB [27]. By comparing a map of HLRs with an Envision- 
generated map of the landscape, we will test the hypothesis that we can predict a region's response to climate change simply by knowing its HLR category. A parallel approach to produce a classification of geographic regions based on social and economic attributes could be used to develop a new typology of adaptive capacity regions (ACRs) to test the hypothesis that we can predict human impacts from water scarcity simply by knowing its ACR category. Such a classification would allow us to test the hypothesis that we can predict human impacts from water scarcity simply by knowing its ACR category by comparing a map of ACRs with an Envision-generated map of the landscape,

Patterns of stocks and flows for different types of capital in different parts of the basin may also be related to their vulnerability to water scarcity, as described in section 3.4 above. Identifying those patterns associated with either resilience or vulnerability to water scarcity in different geographic units on the landscape would not only provide a means to identify locations of concern, but would also give managers insights into what actions (for example, investment in restoring natural capital, or an increase in financial, physical, human or social capital) might be most likely to result in a change from vulnerability to resilience.

\section{Initial findings and summary}

In the initial phase of this project, attention to both theory and practical aspects of the research have helped us develop a conceptual foundation and approach in which the Envision model can be used both as a tool to guide decision-making concerning water scarcity in the WRB and as an opportunity to examine the dynamics of a river basins as a CAS. Our study of the WRB as a CAS and investigation of system dynamics as they relate to water scarcity will provide us with the opportunity to test some of the assumptions and hypotheses of resilience theory. This work will build a modeling tool to guide policy in the region and identify data gaps and research needs where the data for asking and answering key questions are not available. It will also allow us to take the next steps to advance the theory of resilience and understand the behavior of social-ecological systems in response to change. Our project provides an organizing theoretical approach to structure comparisons of river basins in the world and assess their vulnerability to water scarcity and vulnerability at multiple scales.

\section{References}

[1] Holling, C., Resilience and stability of ecological systems. Annual Reviews in Ecology and Systematics, 4, pp. 1-23, 1973.

[2] Levin, S., Ecosystems and the biosphere as complex adaptive systems. Ecosystems, 1, pp. 431-436, 1998.

[3] Gunderson, L.H. \& Holling, C.S., (eds.). Panarchy: Understanding Transformations in Human and Natural Systems. Island Press, Washington DC, 2002.

[4] Walker, B.H. \& Salt, D., Resilience Thinking: Sustaining Ecosystems and People in a Changing World. Island Press, Washington DC, 2006. 
[5] The Resilience Alliance, http://www.resalliance.org.

[6] Carpenter, S.R., Ludwig, D. \& Brock, W.A., Management of eutrophication for lakes subject to potentially irreversible change. Ecological Applications, 9, pp. 751-771, 1999.

[7] Abel, N., Cumming, D.H.M. \& Anderies, J.M., Collapse and reorganization in social-ecological systems: questions, some ideas, and policy implications. Ecology and Society, 11(1), pp. 17. [online] URL: http://www.ecologyandsociety.org/vol11/iss1/art17/, 2006.

[8] Schlüter, M. \& Pahl-Wostl, C., Mechanisms of resilience in common-pool resource management systems: an agent-based model of water use in a river basin. Ecology and Society, 12(2), pp. 4- [online] URL: http://www.ecologyandsociety.org/vol12/iss2/art4/, 2007.

[9] Carpenter, S., Walker, B., Anderies, J.M. \& Abel, N., From metaphor to measurement: resilience of what to what? Ecosystems, 4, pp. 765-781, 2001. DOI: $10.1007 / \mathrm{s} 10021-001-0045-9$.

[10] Folke, C., Resilience: the emergence of a perspective for social-ecological systems analyses. Global Environmental Change 16, pp. 253-266, 2006.

[11] Hulse, D.W., Gregory, S.V. \& Baker, J.P. (eds.), Willamette River Basin: Trajectories of Environmental and Ecological Change. Oregon State University Press: Corvallis, Oregon, USA, 2002.

[12] Nolin, A. \& Daly, C., Mapping "at risk" snow in the Pacific Northwest. Journal of Hydrometeorology, 7, pp. 1164-1171, 2006.

[13] Berger, C., Annear, R. L., \& Wells, S. A., Lower Willamette River Model: Model Calibration. Technical Report EWR-2-01, Department of Civil Engineering, Portland State University, Portland, Oregon, 2001.

[14] Baker, J.P., Hulse, D.W., Gregory, S.V., White, D., Van Sickle, J., Berger, P.A., Dole, D. \& Schumaker, N.H., Alternative futures for the Willamette River Basin, Oregon. Ecological Applications, 14(2), pp. 313-324, 2004.

[15] Chang, H. \& Jung, I.-W., Spatial and temporal changes in runoff caused by climate change in a complex large river basin in Oregon. Journal of Hydrology, 388(3-4), pp. 186-207, 2010.

[16] Moradkhani, H. \& Meier, M., Long-lead water supply forecast using largescale climate predictors and independent component analysis. Journal of Hydrologic Engineering, 15(10), doi: 10.1061/ASCE-HE.19435584.0000246, 2010.

[17] Graves, D. \& Chang, H., Hydrologic impacts of climate change in the upper Clackamas basin of Oregon. Climate Research, 33(2), pp. 143-157, 2007.

[18] Tallis, H. \& Polasky, S., Mapping and valuing ecosystem services as an approach for conservation and natural-resource management. Annals of the New York Academy of Sciences, 1162, pp. 265-283. doi: 10.1111/j.17496632.2009.04152.x, 2009.

[19] Bolte, J., Hulse, D., Gregory, S. \& Smith, C., Modeling biocomplexity -actors, landscapes and alternative futures. Environmental Modeling and Software, 22(5), pp. 570-579, 2007.

[20] Guzy, M.R., Smith, C.L., Bolte, J.P., Hulse, D.W. \& Gregory, S.V., Policy research employing agent-based modeling to assess future impacts of urban 
expansion onto farm and forest lands. Ecology and Society, 13(1), pp. 37. [online] URL: http://www.ecologyandsociety.org/vol13/iss1/art37/, 2008.

[21] Hulse, D., Branscomb, A., Enright, C. \& Bolte, J., Anticipating floodplain trajectories: a comparison of two alternative future approaches. Landscape Ecology, 2008. DOI:10.1007/s10980-008-9255-2.

[22] Holling C., Cross-scale morphology, geometry and dynamics of ecosystems. Ecological Monographs, 62, 477-502, 1992.

[23] Gunderson, L.H., Holling, C.S., \& Light, S.S., Barriers and Bridges to the Renewal of Ecosystems and Institutions. Columbia University Press: New York, 1995.

[24] Bebbington, A.C., Capitals and capabilities: a framework for analyzing peasant viability, rural livelihoods and poverty. World Development, 27 (12), pp. 2021-2044, 1999.

[25] Goodwin, N.R., Five kinds of capital: useful concepts for sustainable development. Global Development And Environment Institute Working Paper No. 03-07. Tufts University, Medford MA, 2003. http://ase.tufts.edu/gdae/publications/working_papers/.

[26] Chan, S., McDonnell, J., Bolte, J.P., Morzillo, A.T., Santelmann, M.V. \& Wright, M., Co-learning through stakeholder learning action networks. Forthcoming.

[27] EPA NSCEP http://www.epa.gov/wed/pages/research/FEB\%20intranet.pdf. 